\title{
Study of internal versus external gettering of iron during slow cooling processes for silicon solar cell fabrication
}

\author{
Jasmin Hofstetter, Jean F. Lelièvre, Carlos del Cañizo, Antonio Luque \\ Instituto de Energía Solar, Universidad Politécnica Madrid, Avd. Complutense, 28040 Madrid, Spain, \\ jasmin.hofstetter@ies-def.upm.es, jflelievre@ies-def.upm.es, canizo@ies-def.upm.es, luque@ies-def.upm.es
}

Keywords: multi-crystalline silicon, slow cooling, phosphorous diffusion gettering

\begin{abstract}
The effect of slow cooling after different high temperature treatments on the interstitial iron concentration and on the electron lifetime of p-type me-Si wafers has been investigated. The respective impacts of internal relaxation gettering and external segregation gettering of metal impurities during an extended phosphorous diffusion gettering are studied. It is shown that the enhanced reduction of interstitial Fe during extended P-gettering is due to an enhanced segregation gettering while faster impurities like $\mathrm{Cu}$ and $\mathrm{Ni}$ are possibly reduced due to an internal gettering effect.
\end{abstract}

\section{Introduction}

The rapid growth of the photovoltaic (PV) sector has led to the development of alternative and cheaper ways of silicon purification. In comparison with electronic grade silicon (eg-Si), a lower quality is acceptable for the so-called solar grade $\mathrm{Si}$ (SoG-Si) and different approaches are currently used to produce it, like the upgrading of metallurgical grade Si (UMG-Si). The use of SoG-Si material results in the need for PV industrials to adapt their fabrication process in order to keep the solar cell efficiency high. However, the implementation of a sophisticated defect engineering might even increase the allowed impurity concentrations in SoG-Si [1]. In this work, the following tools to improve the quality of a multi-crystalline silicon (mc-Si) wafer during the solar cell fabrication process are investigated: (i) extraction of impurities by means of external gettering and (ii) reduction of the interstitial impurity concentration by internal gettering during slow cooling.

While fast cooling leads to supersaturation, spontaneous nucleation and thus to a high density of precipitates, a low cooling rate is supposed to increase the size of existing precipitates while maintaining the total precipitate density low. In other words, precipitates act as internal gettering sites. This hypothesis has been recently confirmed hy Buonassisi et al [2] in cooling experiments with intentionally doped mc-Si. Furthermore, a slow cool down or low temperature annealing after phosphorous diffusion gettering ("extended gettering") has heen shown to increase the electron lifetime in p-type mc-Si wafers to an extent much greater than a standard gettering step at constant temperature $[3,4,5,6]$. So far it has not been clear whether internal (relaxation) gettering or external (segregation) gettering is the dominant process during a slow cool down under the presence of the phosphorous gettering layer. In order to separate and understand the phenomena occurring during extended gettering, adjacent wafers from a nic-Si ingot have been subjected to high temperature treatinents followed by a slow cool down with and without the presence of an external $P$ gettering layer. Respective changes in the electron lifetime and in the concentration of interstitial iron are ineasured in order to evaluate the respective inpact of internal versus external gettering. 


\section{Experimental}

Three sets of adjacent, p-type, $5 \times 5 \mathrm{~cm}^{2}$ cast mc-Si wafers ( $\mathrm{E}, \mathrm{G}, \mathrm{I}$ ) have been subjected to different temperature treatments in different gaseous ambiances. All wafers belong to the same ingot but two wafer sets ( $\mathrm{G}$ and $\mathrm{I}$ ) originate from the border of the ingot. All wafers have been subjected to a $\mathrm{CP} 4$ etch, RCA cleans and an $\mathrm{HF}$ dip before surface passivating $\operatorname{SiN}_{x}$ layers have been deposited on both sides of the wafers. The average initial electron lifetime $\tau$ of cach wafer has becn measured by means of Quasi-Steady-State Photoconductance (QSSPC) method with a Sinton WC-100 tool. Lifetime mappings have becn recorded with the microwavePhotoconductance Decay $(\mu-P C D)$ tool from Semilab. The concentration of interstitial iron $\left[\mathrm{Fe}_{i}\right]$ has been determined by means of iron boron pair dissociation [7]. The mean initial lifetimes of the different wafer groups $\mathrm{E}, \mathrm{G}$ and $\mathrm{I}$ are given in Tab. 1. The initial values of $\left[\mathrm{Fe}_{i}\right]$ are also shown. Then, $\mathrm{SiN}_{x}$ layers have been removed and again, wafers have been cleaned an HF dipped.

Table 1: Mean initial lifetimes and interstitial iron concentrations $\left[\mathrm{Fe}_{i}\right]$ of the different wafer groups E, G and I; errors are standard deviations within one wafer group

\begin{tabular}{cccc}
\hline \hline & $\mathrm{E}$ & $\mathrm{G}$ & $\mathrm{I}$ \\
\hline \hline$\tau_{\text {ini }}[\mu \mathrm{s}]$ & $(17 \pm 9)$ & $(9 \pm 3)$ & $(8 \pm 2)$ \\
{$\left[F e_{i}\right]\left[\mathrm{cm}^{-3}\right]$} & $(5 \pm 3) \cdot 10^{11}$ & $(1 \pm 0.5) \cdot 10^{12}$ & $(1.4 \pm 0.4) \cdot 10^{12}$ \\
\hline \hline
\end{tabular}

Conscquently, wafers from each set have been subjected to one of the following temperature treatments:

Oxidation at $850^{\circ} \mathrm{C}$ during $20 \mathrm{~min}$ in a dry $\mathrm{O}_{2}$ ambiance followed by a

Of: fast cool down to room temperature (RT), temperature profile $\mathrm{f}$

Os: slow cool down to RT, temperature profile s

Ns: Annealing at $850^{\circ} \mathrm{C}$ during $20 \mathrm{~min}$ in a $\mathrm{N}_{2}$ ambiance followed by a slow cool down to RT, temperature profile $\mathrm{s}$

Phosphorous diffusion gettering at $850^{\circ} \mathrm{C}$ during 20 min using a $\mathrm{POCl}_{3}$ source followed by a Pf: fast cool down to RT, temperature profile $\mathrm{f}$

Ps: slow cool down to RT, temperature profile s

The applied temperature profiles $\mathrm{f}$ and $\mathrm{s}$ are shown in Fig. 1. Tab. 2 shows the distribution of

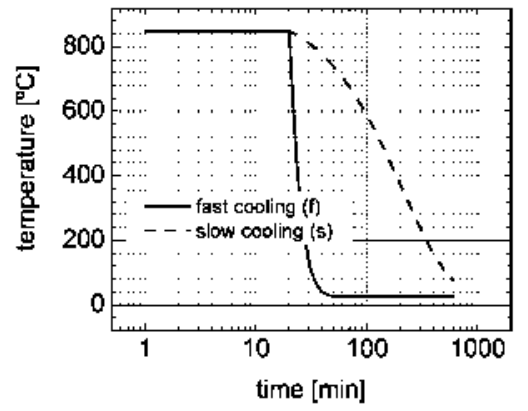

Fig. 1: Fast cooling (f) and slow cooling (s) temperature profiles
Table 2: Distribution of the wafers on the different temperature treatments

\begin{tabular}{cccc}
\hline \hline ambiance & T profilc & wafers & trcatmcnt \\
\hline \hline $\mathrm{O}_{2}$ & $\mathrm{f}$ & $\mathrm{G}, \mathrm{E}, \mathrm{I}$ & $\mathrm{Of}$ \\
$\mathrm{O}_{2}$ & $\mathrm{~s}$ & $\mathrm{G}, \mathrm{E}, \mathrm{I}$ & $\mathrm{Os}$ \\
$\mathrm{N}_{2}$ & $\mathrm{~s}$ & $\mathrm{G}, \mathrm{E}, \mathrm{I}$ & $\mathrm{Ns}$ \\
$\mathrm{POCl}_{3}$ & $\mathrm{f}$ & $4 \mathrm{xG}, 4 \mathrm{xE}, 4 \mathrm{xI}$ & $\mathrm{Pf}$ \\
$\mathrm{POCl}_{3}$ & $\mathrm{~s}$ & $\mathrm{G}, \mathrm{E}, \mathrm{I}$ & $\mathrm{Ps}$ \\
\hline \hline
\end{tabular}

the wafers used for the different temperature treatments. Afterwards, the surface of each wafer has been etched off and a further cleaning procedure and HF dip have been applied. Agair, $\operatorname{SiN}_{x}$ layers have been deposited on each side of the wafers in order to passivate the surface. Finally, 
the resulting average lifetimes, lifetime mappings and $\left[\mathrm{Fe}_{i}\right]$ have been measured as described above.

\section{Results}

Figs. 2 and 3, respectively, show the mean relative changes in lifetime, $\Delta \tau / \tau_{\text {ini }}$, and in the interstitial iron concentration, $\Delta\left[F e_{i}\right] /\left[F_{i}\right]_{i n i}$, after the different temperature treatments.

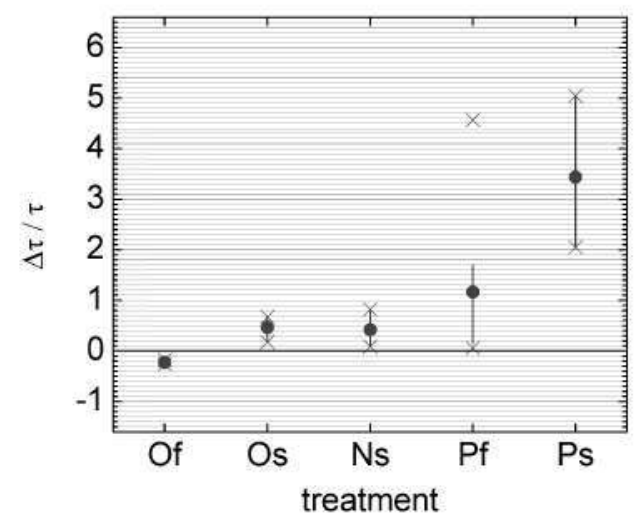

Fig. 2: Relative changes in the average electron lifetime after the different treatments; dots are mean values, error bars are standard errors and crosses are minimum and maximum values; see Tab. 2 for nomenclature

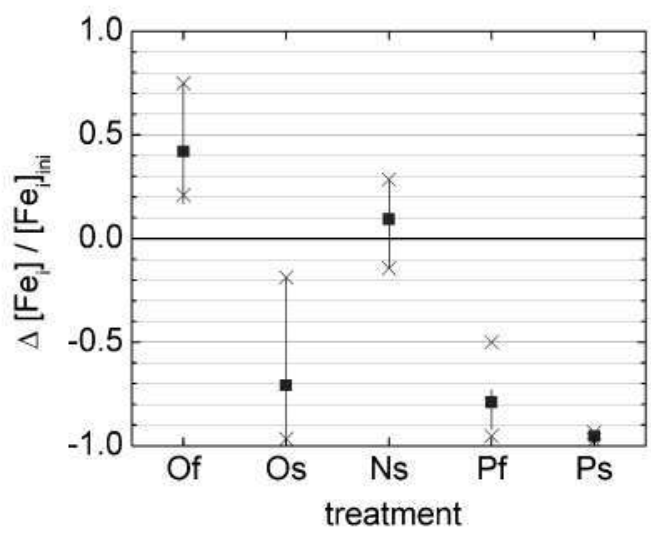

Fig. 3: Relative changes in the average $\left[\mathrm{Fe}_{i}\right]$ after the different treatments; squares are mean values, error bars are standard errors and crosses are minimum and maximum values; see Tab. 2 for nomenclature

Annealing and cooling in an oxidizing ambiance. All wafers that have been subjected to an oxidation at $850^{\circ} \mathrm{C}$ followed by a fast cool down to RT show a degradation of around $20 \%$ in the average electron lifetime (see Fig. 2, Of). Such a "thermal degradation" is commonly observed after high temperature steps in mc-Si [8]. It is mainly due to the dissolution of impurity precipitates at high temperatures that do not re-precipitate during the fast cool down to RT. In fact, corresponding to the lifetime degradation, a small increase in $\left[\mathrm{Fe}_{i}\right]$ of about $40 \%$ has been measured for these wafers (see Fig. 3, Of). In the lifetime mapping of such a fast cooled wafer the lifetime degradation especially of good lifetime areas can be observed (compare Figs. 4(a) \& 4(b)).

In contrast, all wafers that have been subjected to an oxidation followed by a slow cool down to RT show a mentionable lifetime improvement of about $50 \%$ at average (see Fig. 2, Os). Especially low lifetime areas like border regions improve markedly during the slow cooling. This effect is observed very clearly comparing the lifetime mappings of wafer GOs before and after the temperature treatment (Figs. 4(c) \& 4(d)). Correspondlingy, an average decrease of $\left[\mathrm{Fe}_{i}\right]$ of about $70 \%$ has been measured (see Fig. 3, Os). Due to interfacial stress during oxide layer formation an enhanced impurity diffusion towards the surface has been observed especially during cooling to RT [9]. This surface diffusion might overlap or even dominate the effect of internal gettering during slow cooling. Thus, the annealing and slow cooling step has been repeated in $\mathrm{N}_{2}$ ambiance in order to avoid the formation of an oxide layer and the related stresses.

Annealing and slow cooling in a $\mathrm{N}_{2}$ ambiance. All wafers that have been annealed and slowly cooled in $\mathrm{N}_{2}$ ambiance exhibit an increase in lifetime after the temperature treatment 


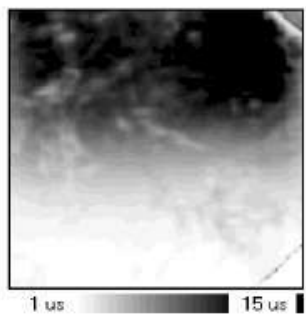

(a) initial GOf, $\tau_{\text {ini }}=11 \mu \mathrm{s}$, $\mathrm{Fe}_{i, \text { in } i}=8 \cdot 10^{11} \mathrm{~cm}^{-3}$

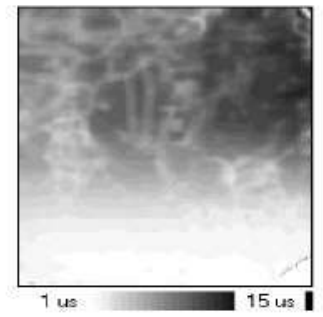

(b) final GOf, $\tau_{\text {fin }}=8 \mu \mathrm{s}$,

$\mathrm{Fe}_{i, f i n}=1.0 \cdot 10^{12} \mathrm{~cm}^{-3}$

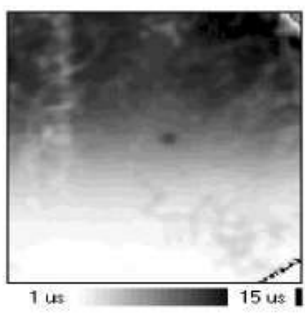

(c) initial GOs, $\tau_{\text {in } i}=10 \mu \mathrm{s}$,

$\mathrm{Fe}_{i, i n i}=1.0 \cdot 10^{12} \mathrm{~cm}^{-3}$

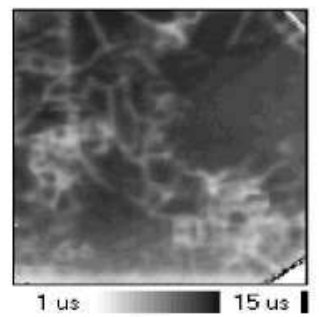

(d) final GOs, $\tau_{\text {fin }}=12 \mu \mathrm{s}$,

$\mathrm{Fe}_{i, f \text { in }} \leq 5 \cdot 10^{10} \mathrm{~cm}^{-3}$

Fig. 4: Electron lifetime mappings ( $\mu$-PCD) of i) wafer GOf before (a) and after (b) an oxidation followed by a fast cool down and ii) wafer GOs before (c) and after (d) oxidation followed by a slow cool down.

which lies around $40 \%$ (see Fig. 2, Ns). Nevertheless, no significant change in $\left[\mathrm{Fe}_{i}\right]$ has been measured for any of these wafers (see Fig. 3, Ns). Figs. 5(a) - 5(d) show the initial and final lifetime mappings of wafers GNs and ENs, respectively. The mean electron lifetimes as well as $\left[\mathrm{Fe}_{i}\right]$ before and after the temperature treatment are also shown. The lifetime mappings reveal that especially good lifetime areas improve during the slow cool down. This results in a strong increase in lifetime for wafer ENs from 9 to $17 \mu$ s. In contrast, low lifetime areas like the border of wafer GNs remain the same so that only a total increase in lifetime of about $1 \mu$ s is observed for wafer GNs.

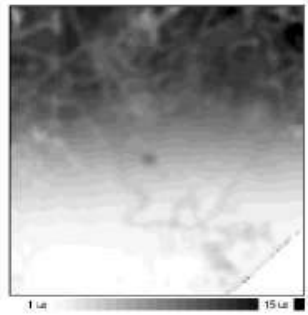

(a) GNs initial, $\quad \tau_{\text {ini }}=8 \mu \mathrm{s}$, $\mathrm{Fe}_{i, \text { in } i}=1.4 \cdot 10^{12} \mathrm{~cm}^{-3} \mathrm{Fe}_{i, \text { fin }}=1.6 \cdot 10^{12} \mathrm{~cm}^{-3}$

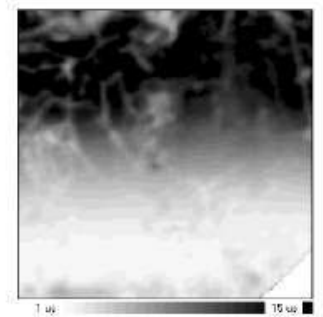

(b) GNs final, $\quad \tau_{\text {fin }}=9 \mu \mathrm{s}$,

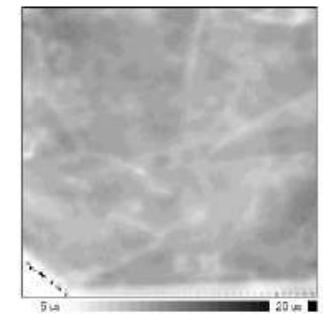

(c) ENs initial, $\quad \tau_{\text {ini }}=9 \mu \mathrm{s}$, $\mathrm{Fe}_{i, \text { in } i}=6 \cdot 10^{11} \mathrm{~cm}^{-3}$

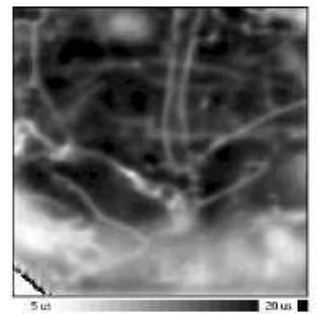

(d) ENs final, $\quad \tau_{\text {fin }}=17 \mu \mathrm{s}$, $\mathrm{Fe}_{i, f i n}=8 \cdot 10^{11} \mathrm{~cm}^{-3}$

Fig. 5: Electron lifetime mappings ( $\mu$-PCD) of wafers GNs and ENs before (a and d) and after (b and d) annealing at $850^{\circ} \mathrm{C}$ in $\mathrm{N}_{2}$ followed by a slow cool down; note the different lifetime scales for the two different wafers.

Standard versus extended phosphorous diffusion gettering. Generally, the lifetime of all phosphorous diffused wafers increases during the two different P-gettering treatments. Wafers that have been subjected to a standard gettering step show a mean lifetime enhancement of about $115 \%$ (see Fig. 2, Pf). Representatively, Figs. 6(a) and 6(b) show the initial and final lifetime mapping of wafer IPf4. An overall improvement of the electron lifetime is observed after the standard gettering step and the average lifetime has increased from 8 to $18 \mu \mathrm{s}$. Especially areas of low initial lifetime improve to an extent that they cannot be distinguished from other areas in the final lifetime mapping. Corresponding to the lifetime improvement, a reduction of $\left[\mathrm{Fe}_{i}\right]$ of about $80 \%$ has been measured at average (see Fig. 3, Pf).

The greatest lifetime improvement has been measured on wafers that have been subjected to an extended P-diffusion gettering. The mean lifetime increase is about three times the initial 


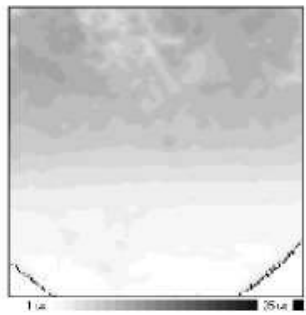

(a) IPf4, $\quad \tau_{\text {ini }}=8 \mu \mathrm{s}$, $\mathrm{Fe}_{i, i n i}=1.2 \cdot 10^{12} \mathrm{~cm}^{-3}$

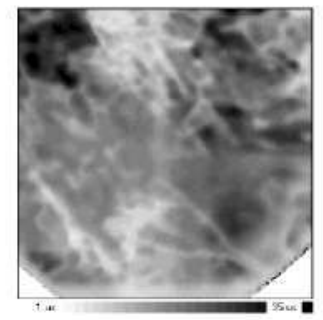

(b) final IPf4, $\tau_{\text {fin }}=18 \mu \mathrm{s}$, $\mathrm{Fe}_{i, f \text { in }}=8 \cdot 10^{10} \mathrm{~cm}^{-3}$

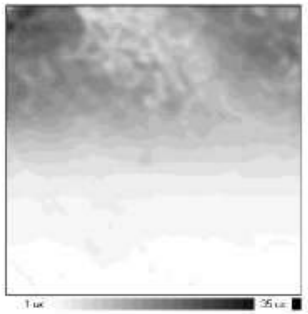

(c) initial IPs, $\quad \tau_{\text {ini }}=7 \mu \mathrm{s}$, $\mathrm{Fe}_{i, i n i}=1.2 \cdot 10^{12} \mathrm{~cm}^{-3} \mathrm{Fe}_{i, f i n} \leq 5 \cdot 10^{10} \mathrm{~cm}^{-3}$

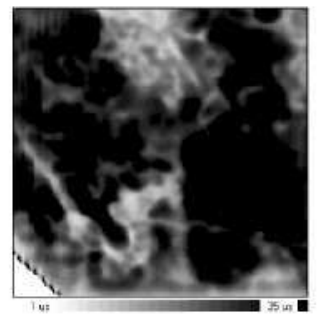

(d) final IPs, $\tau_{\text {fin }}=30 \mu \mathrm{s}$,

Fig. 6: Electron lifetime mappings ( $\mu$-PCD) of i) wafer IPf4 before (a) and after (b) a standard Pgettering diffusion and ii) wafer IPs1 before (c) and after (d) an extended P-gettering diffusion.

lifetime (see Fig. 2, Ps) but lifetime enhancements of up to five times the initial value have been measured. In particular wafers of low initial lifetime show the highest lifetime improvements during the extended gettering step. The lifetime mappings in Figs. 6(c) and 6(d) show that the medial electron lifetime of wafer IPs has increased from 7 to $30 \mu \mathrm{s}$. At an average, $\left[\mathrm{Fe}_{i}\right]$ is reduced by $90 \%$ during an extended gettering step (see Fig. 3, Ps) and for some wafers it falls below the detection limit of about $5 \cdot 10^{10} \mathrm{~cm}^{-3}$.

\section{Discussion}

Our results confirm that an oxidation followed by a fast cool down leads to a thermal degradation of mc-Si wafers as described above. In contrast, when the oxidation step is followed by a slow cool down to RT, the electron lifetime improves and $\left[\mathrm{Fe}_{i}\right]$ is reduced. The question is if this iron reduction is due to an internal gettering of iron to precipitation sites or to an external gettering to the surface oxide [9]. In comparison, for annealed and slowly cooled wafers in $\mathrm{N}_{2}$ ambiance a somewhat smaller lifetime improvement is found and the final interstitial iron concentration approximately equals the initial concentration. The slow cooling rate only leads to a small internal gettering effect for iron: atoms that might have dissolved during the high temperature step are able to re-precipitate but no further reduction of dissolved iron takes place. This comparison indicates that the interstitial iron reduction after oxidation and slow cooling results from iron diffusion to the surface oxide layer and is not due to internal gettering.

Although the iron concentration remains constant after slow cooling in $\mathrm{N}_{2}$, the electron lifetime improves noticeably. This improvement might be due to the internal gettering of other impurity types different from iron. The diffusivity of interstitial iron is supposed to be too low to reach existing precipitation sites during the slow cool down. Other lifetime degrading impurities that are frequently found in mc-Si and that have higher diffusivities than iron are copper and nickel. Applying Ham's law [10], we have performed simple calculations that take into consideration the diffusivity and the solid solubility of the respective impurity type taken from [11]. A typical radius and density of existing metal precipitates for cast mc-Si have been assumed [12]. Results show that during the applied slow cooling the respective dissolved metal concentrations can be reduced below $10^{9} \mathrm{~cm}^{-3}$ for $\mathrm{Cu}$ and below $10^{11} \mathrm{~cm}^{-3}$ for Ni. These values are well below the critical concentrations at which $\mathrm{Cu}$ and $\mathrm{Ni}$ affect the performance of a p-type Si solar cell $[13,1]$ so that an internal gettering of $\mathrm{Cu}$ and Ni might actually be the cause for the observed lifetime improvement.

The lifetime of the border region of the ingot does not improve during slow cooling in $\mathrm{N}_{2}$ (see Fig. 5(b)). As the internal gettering during slow cooling does not reduce the net concen- 
tration of interstitial iron, the lifetime of the border region might be mainly limited by iron contamination. On the contrary, the electron lifetime of wafers from the center of the ingot improves considerably during the same temperature treatment (Fig. 5(d)). Assuming that an internal gettering during slow cooling is taking place for fast diffusing metal impurities like $\mathrm{Cu}$ and $\mathrm{Ni}$, the initial lifetime of the center of the ingot might be limited by those fast diffusing impurities.

In contrast to internal gettering, both standard and extended P-diffusion gettering are very effective methods to reduce the dissolved iron content in the mc-Si wafers under investigation (Fig. 3, Pf and Ps). During an extended P-diffusion gettering, at average a $10 \%$ higher reduction of interstitial iron has been achieved than during a standard gettering step. As we have seen that internal gettering during the applied slow cooling has not lead to a net reduction of $\left[\mathrm{Fe}_{i}\right]$, this further reduction has to be explained by an enhanced external gettering. With decreasing temperature, the segregation coefficient of the P-diffused layer increases [14] which results in a higher driving force for metals to segregate. During fast cooling, our results suggest that interstitial iron atoms do not reach the external gettering layer. In contrast, during a slow cool down, their diffusivity only decreases gradually with temperature so that a further reduction of iron is achieved.

The increased iron reduction after extended $\mathrm{P}$-gettering is also reflected in a stronger improvement of the electron lifetime in comparison to standard gettering. The highest lifetime improvements have been ohserved for group I and G wafers that originate from the border of the ingot. This observation supports the assumption that low lifetimes at the border of the ingot are strongly correlated to iron contamination. Additionally to an enhanced segregation gettering of iron and probably an enhanced segregation gettering of other impurity types, an internal gettering of fast impurities during extended P-gettering might also contribute to the strong lifetime improvement. A comparison of the lifetime mappings in Figs. 6(b) and 6(d) reveals that only good lifetime areas improve further during the extended P-gettering while low lifetime areas such as grain boundaries and areas with high dislocation densities do not improve. Thus, these characteristic precipitation sites might serve as additional sinks for fast impurity atoms during extended gettering.

\section{Conclusions}

Without the presence of an external gettering layer, fast cooling after a high temperature step leads to a thermal lifetime degradation in mo-Si wafers whereas a slow cool down leads to an internal gettering effect and an improvement in lifetime. It allows moderately diffusing impurity atoms like Fe to re-precipitate while the concentration of fast diffusing interstitial impurity atoms like $\mathrm{Cu}$ and $\mathrm{Ni}$ might be decreased.

Slow cooling under the presence of an external gettering layer leads to an improved reduction of interstitial iron and to an increased electron lifetime in comparison to a fast cool down. But with respect to our results the improved iron reduction seems to be only caused by an enhanced segregation gettering of iron atoms to the P-diffused layer. For faster impurity atoms, segregation gettering as well as relaxation gettering may take place during extended P-gettering and the decrease of their dissolved concentration might contribute to the the strong increase of the electron lifetime.

\section{Acknowledgments}

This work has been partially funded by the Spanish Ministerio de Ciencia e Innonacion, through Thincell project (TEC2008-06798-C03-02). The additional support through the MIT-Spain/La 
Cambra de Barcelona Seed Fund is gratefully acknowledged. Furthermore, the authors would like to thank Prof. Tonio Buonassisi for helpful discussions.

\section{References}

[1] J. Hofstetter, J. F. Lelièvre, C. del Cañizo, and A. Luque: Materials Science and Engineering; B, vol. 159-160 (2009), pp. 299-304

[2] T. Buonassisi, A. Istratov, M. Marcus, S. Peters, C. Ballif, M. Heuer, T. Ciszek, Z. Cai, B. Lai, R. Schindler, and E. Weber: in Proc. 31st IEEE PVSC, Lake Buena Vista, Florida (2005), pp. $1027-1030$

[3] P. Manshanden and L. Geerligs: Sol. Energy Mater. Sol. Cells, vol. 90 (2006), pp. 998-1012

[4] D. Schwaderer, S. Riepe, H. Habenicht, O. Schultz, and W. Warta: in Proc. 22nd EUPVSEC, Milan, Italy (2007).

[5] J. Tan, A. Cuevas, D. Macdonald, N. Benuett, I. Romijn, T. Trupke, aud R. Bardos, in Proc. 22nd EUPVSEC, Milan, Italy (2007), pp. 1309-1313

[6] M. Rinio, A. Yodyunyong, M. Pirker, S. Keipert, P. Wang, T. Buonassisi, and D. Borchert, in Proc. 23nd EUPVSEC, Valencia, Spain (2008).

[7] D. H. Macdonald, L. J. Gerligs, , and A. Azzizi: J. Appl. Phys., vol. 95, no. 3 (2004) pp. 10211028

[8] S. Ponce-Alcántara, C. del Cañizo, and A. Luque: Solar Energy Materials \& Solar Cells, vol. 87 (2005), pp. 411-421

[9] S. K. Gandhi, VLSI Fabrication Principles. John Wiley \& Son (1983).

[10] F. Ham: J. Phys. Chem. Solids, vol. 6 (1958), p. 335

[11] K. Graff, Metal impurities in silicon device fabrication, 1st ed. Springer-Verlag (1995).

[12] T. Buonassisi, A. Istratov, M. Marcus, B. Lai, Z. Cai, S. Heald, and E. Weber, Nat. Mater, vol. 4 (2005), pp. 676-679

[13] J. R. Davis, A. Rohatgi, R. H. Hopkins, P. D. Blais, T. Rai-Choudhury, J. R. McCormick, and H. C. Mollenkopf, IEEE T. Electron. Dev., vol. 27 (1980), pp. 677-687

[14] M. B. Shabani, T. Yamashita, and E. Morita, Solid state phenomena, vol. 131-133 (2008), pp. $399-404$ 